\title{
The prospects of emotional dogmatism
}

\author{
Eilidh Harrison ${ }^{1}$
}

Accepted: 22 September 2020/Published online: 6 October 2020

(C) The Author(s) 2020

\begin{abstract}
The idea that emotional experience is capable of lending immediate and defeasible justification to evaluative belief has been amassing significant support in recent years. The proposal that it is my anger, say, that justifies my belief that I've been wronged putatively provides us with an intuitive and naturalised explanation as to how we receive epistemic justification for a rich catalogue of our evaluative beliefs. However, despite the fact that this justificatory thesis of emotion is fundamentally an epistemological proposal, comparatively little has been done to explicitly isolate what it is about emotions that bestows them with justificatory ability. The purpose of this paper is to provide a novel and thorough analysis into the prospects of phenomenology-based-or dogmatist-views of emotional justification. By surveying and rejecting various instantiations of the emotional dogmatist view, I endeavour to provide an inductive case for the conclusion that emotional phenomenology cannot be the seat of the emotions' power to immediately justify evaluative belief.
\end{abstract}

Keywords Emotion · Phenomenal dogmatism - Epistemic justification - Seemings · Phenomenology

\section{Introduction}

The idea that emotional experience is capable of lending immediate and defeasible justification to evaluative belief has been gaining significant traction in recent years. The proposal that it is my anger, say, that justifies me in believing that I've been

Eilidh Harrison

e.harrison.1@research.gla.ac.uk

1 Philosophy, School of Humanities, University of Glasgow, 67 - 69 Oakfield Avenue, Glasgow G128QQ, UK 
offended putatively provides us with an intuitive and naturalised explanation as to how we receive epistemic justification for a rich catalogue of our evaluative beliefs. With many notable advocates, this justificatory thesis of emotion is fast becoming a central facet in how we conceive of the emotions' epistemic role. ' Interestingly, however, comparatively little of the philosophical literature has been dedicated to explicitly isolating what it is about emotional experience that bestows it with the ability to immediately and defeasibly justify belief. The aim of this paper is to present and evaluate an internalist view of emotional justification, namely, one which identifies emotional phenomenology as the source of the emotions' ability to justify evaluative belief.

Support for a phenomenology-based view can be found in various suggestive comments made by notable authors in the philosophy of emotion. Goldie (2004), for example, argues on behalf of an account of emotion "where the feelings involved are at center stage, playing a centrally important epistemic role in revealing things about the world" (p. 92). On a similar note, Tappolet (2016) argues that emotional experiences uniquely "allow us to be aware of certain features of the world" (p. 18), while Johnston (2001) claims that the epistemic import of affective experiences is rooted in their providing us with "affective disclosure" (p. 213) of evaluative properties. The focus of these claims on 'feelings', 'awareness', and 'affective disclosure' certainly seems at least suggestive of the fact that these authors take the phenomenal properties instantiated by emotional experience-the what-it-is-like for a subject to undergo emotional experience-to bear epistemic significance.

So, how might we construct a phenomenology-based view of emotional justification? One plausible way is to build it as relevantly analogous to phenomenal dogmatism. For phenomenal dogmatists, a perceptual experience that makes it seem to you that $p$ immediately and defeasibly justifies you in believing that $p$. Given that phenomenal dogmatism is an attractive internalist view of justification that places epistemic importance on experiential phenomenology, we can draw up an emotional analogue accordingly, such that an emotional experience that makes it seem to you that $e$ (where $e$ signifies a proposition attributing an evaluative property to an object) immediately and defeasibly justifies you in believing that $e$. Call this emotional dogmatism. Here, by surveying and rejecting several instantiations of the emotional dogmatist view, I endeavour to build an inductive case for the conclusion that the phenomenal character of emotional experience cannot be what makes it capable of immediately and defeasibly justifying evaluative belief.

The structure of this paper is as follows. $\$ 2$ begins by further elucidating the phenomenal dogmatist view and presenting the analogous emotional dogmatist thesis. In $\$ 2.1$, I argue that basic dogmatism, which requires only that the experience bears unqualified seeming phenomenal character, falls foul to a worrisome overgeneralisation problem. In $\S 3$, I suggest that a restrictive account of phenomenal dogmatism based on Chudnoff's presentationalism is better placed for an investigation into the prospects of an analogous emotional dogmatist view. $\$ 3.1$ then presents a novel objection against this view, namely, that there is no plausible

\footnotetext{
${ }^{1}$ See, for instance, Cowan (2018), Döring (2007), Pelser (2014), and Tappolet (2016).
} 
way of spelling out what seeming awareness of truth-makers for evaluative propositions consists in. $\S 4$ then considers and rejects alternative restricted views based on McGrath's and Markie's respective accounts of restricted phenomenal dogmatism. Finally, I conclude that, while emotional seeming states might be capable of transmitting justification to evaluative belief mediated by other mental states and beliefs, we have good reason to believe that they cannot bear immediate justificatory power.

\section{Basic emotional dogmatism}

Let us understand phenomenal dogmatism as follows:

Phenomenal Dogmatism (PD): if it perceptually seems to $\mathrm{S}$ that $p$, then, in the absence of defeaters, $\mathrm{S}$ thereby has [immediate] justification for believing that p. (Tucker 2013, p. 2).

Some clarifications are in order. First, PD is an internalist view of justification insofar as it identifies factors internal to the agent (i.e. an agent's seeming states) as sole epistemic justifiers. Second, and importantly, PD is a thesis about immediate justification, i.e. justification which exists independently of any inferential connections to other justified beliefs. Third, identifying the source of an experience's justificatory power in its bearing the character of 'seeming to $S$ that $p$ ' is to identify it in the experience's phenomenal character, i.e. the something-thatit-is-like for the subject to undergo the perceptual experience. Fourth, 'seemings' are typically taken to be non-doxastic propositional attitudes. Finally, while the nature of seeming phenomenal character can be difficult to elucidate in writing, it will be sufficient for our purposes to conceive of it along similar lines to the way in which Tucker (2010) describes it, i.e. seemings instantiate the phenomenal property of asserting or insisting to you that the content of the experience obtains.

Insofar as we're interested in building an account of emotional epistemology on the basis of PD, we can conceive of emotional dogmatism as follows:

Emotional Dogmatism (ED): if it emotionally seems to $\mathrm{S}$ that $e$ (where $e$ signifies a proposition which attributes an evaluative property to an object) then, in the absence of defeaters, $S$ thereby has immediate justification for believing that $e$.

On this view, just as my visual seeming experience of the blue mug can immediately and defeasibly justify my belief that there is a blue mug, my emotional seeming experience of awe towards a painting can immediately and defeasibly justify me in believing that the painting is beautiful. This view is attractive for a number of reasons. First, PD is praised in virtue of its ability to provide a simple and intuitive explanation as to how we receive epistemic justification for our beliefs about the world; we're justified in believing what we do because of the way the world appears to us in our perceptual experience. Analogously, for ED, we're justified in our evaluative beliefs about the world because of the way it appears to us in our emotional experience. Secondly, given the focus on immediate justification, 
PD provides an antidote to pernicious sceptical worries pertaining to the justificatory status of our everyday beliefs about the sensible world. Epistemic justification comes at a low price for PD in virtue of all that's required is that our perceptual experiences bear the right sort of 'seeming' character; the justification need not be mediated via relations to other justified beliefs. Insofar as ED is built on the foundations of PD, it can provide an analogous remedy for sceptical worries pertaining to the justificatory status of our everyday evaluative beliefs. Finally, given the importance of justification for the acquisition of further epistemic goods, dogmatist views can provide a substantive epistemic yield which extends beyond justified belief and plausibly into the domain of both perceptual and evaluative knowledge and understanding.

\subsection{Objection: an over-generalisation problem}

However, a worry with identifying an experience's justificatory power in its bearing unqualified seeming phenomenal character is that the theory lacks the ability to exclude epistemically problematic cases. A popular way of presenting this challenge is in terms of the following example from Markie (2005):

Suppose that we are prospecting for gold. You have learned to identify a gold nugget on sight but I have no such knowledge. As the water washes out of my pan, we both look at a pebble, which is in fact a gold nugget. My desire to discover gold makes it seem to me as if the pebble is gold; your learned identification skills make it seem that way to you. According to [PD], the belief that it is gold has prima facie justification for both of us. (p. 356-357).

This problem constitutes a serious threat for PD. The possibility of states like desires manipulating the content of seemings, and thereby having an influence over which of our beliefs enjoy immediate justification, is worrisome for any theory which attributes such epistemic significance to these seemings. Indeed, consider an emotional case. To borrow an example from Brady (2013, p. 87), suppose that I'm on the hiring committee for a job, and upon interviewing a particular candidate, I find myself experiencing a negative emotion that makes it seem to me that this candidate is duplicitous or untrustworthy. It would be implausible to claim that this emotion alone is capable of immediately justifying my belief that the candidate is duplicitous on the basis of its bearing seeming phenomenal character. However, insofar as ED only identifies unqualified emotional seemings as justificationconferring states, it lacks the theoretical resources to exclude cases like this. It cannot be true that it's only in virtue of an experience bearing this 'seeming' character that it is capable of justifying the relevant beliefs, or else we would have to concede that the gold prospector's wishfully-produced perceptual belief that the pebble is gold is afforded the same justifying role as the skill-produced belief of the mineral expert, or that the suspicious interviewer's belief is justified on the basis of their rogue emotional experience.

The staunch dogmatist might resist this objection, however. In response to overgeneralisation cases, proponents of these views may bite the bullet and allow that, in virtue of their bearing the right kind of seeming character, experiences like these are 
capable of immediately and defeasibly justifying belief. That is, the dogmatist might be perfectly happy to concede that their theory generalises to experiences like those of Markie's gold-prospector or the suspicious interviewer, but deny that this is particularly problematic. It may be counterintuitive to those who aren't naturally inclined to internalist views, but this isn't a decisive objection insofar as these views can plausibly diagnose the intuitive oddness of these cases in other ways, e.g. by pointing to the fact that it is only defeasible and not ultima facie justification conferred by these experiences, and that our intuitions aren't sufficiently finegrained to track the difference between the two, and to the fact that this justification is easily and often defeated, and so forth. Thus, dogmatism appears to have a relatively straightforward escape clause such that it can disarm worries concerning the apparent profligacy of the account.

This form of bullet-biting strikes me as implausible. To illustrate why, consider a weak-willed agent who finds themselves living within a community of racists, all of whom harbour xenophobic beliefs towards those from a different ethnicity to themselves. Out of a strong desire to fit in with this group, the agent actively engages with these xenophobic beliefs. She listens to racist propaganda, attends community events celebrating the exploits of racist historical figures, and so forth. Over time, she comes to adopt these beliefs herself, such that she forms a network of biases towards particular ethnic groups. As such, upon encountering any person that belongs to such a group, she habitually has the seeming that this person is acting suspiciously.

Plausibly, these xenophobic seemings are attributable to the agent herself and, specifically, to her desire to integrate into her community. She created and is responsible for the formation of those seemings. Dogmatists, in virtue of their commitment to the claim that it is defeasible and not ultima facie justification conferred by experience, can explain why the agent's xenophobic seemings do not justify her in believing that the person from a particular ethnic group is acting suspiciously only if she has an awareness of her experience's etiology. That is, for dogmatists, the justification conferred by the xenophobic seemings is defeated by her awareness of the fact that the seemings are ultimately attributable to her desires. ${ }^{2}$ However, it also seems plausible that, as time passes and she successfully integrates into the community, she comes to forget that her desire to fit in was the source of these xenophobic seemings. Her racist beliefs become such an entrenched part of her cognitive architecture that she no longer questions them nor their origin. ${ }^{3}$ Dogmatism then generates the strange result that the agent is not experientially

\footnotetext{
${ }^{2}$ See Huemer (2013) for the argument that an experience's problematic etiology is epistemically relevant to the justificatory status of the belief only when the subject has an awareness of that etiology.

3 One might object that a case like this, i.e. a case in which an agent has no defeaters for the content of her xenophobic seemings, is unrealistic, given the many reasons that racist individuals typically have for doubting the accuracy of their xenophobic responses. In response, let me clarify that I don't intend for this counterexample to be representative of many real life cases, nor does it need to be in order for it to be successful. All that needs to obtain in order for the point to go through is that it meets the conditions for ED, and, yet, it seems counterintuitive to bestow justificatory power to the xenophobic seemings. For what it's worth, however, it's not obvious to me that this case is particularly contrived or beyond the realm of possibility.
} 
justified in her belief that the person is behaving suspiciously at a time $\mathrm{t}^{1}$ where she is aware that her desire is the origin of the xenophobic seemings, but she is justified on the basis of those seemings at a time $\mathrm{t}^{2}$ where she has forgotten that this is the case. This strikes me as counterintuitive. It's odd to suggest that forgetting something can enhance the positive epistemic status of a belief, especially when that belief is causally traceable and attributable to an agent's epistemically dubious desire. ${ }^{4}$ Dogmatists seem to be getting the wrong result here.

Now, there are two ways in which the defender of ED might respond. First, the dogmatist may argue that, while there is something intuitively problematic about this case, it's not obvious that the problem pertains to the presence of epistemic justification. That is, one might contend that what our intuitions in this case are actually tracking is the agent's moral blameworthiness, or zetetic failings pertaining to her process of poor epistemic inquiry. ${ }^{5}$ If these failings are the source of our intuition that there is something amiss with this case, then the emotional dogmatist is let off the hook insofar as there's not actually anything problematic about bestowing her emotional seemings with justificatory power at $\mathrm{t}^{2}$.

I take it that the best strategy for establishing that there is an epistemic failing here (and, specifically, one pertinent to the presence of justification) is to consider an analogous case in which there are no obvious moral or zetetic failings which plausibly hijack the intuition that there's something amiss with bestowing justificatory power to the emotional seemings. If we neutralise these nonjustificatory failings and there's still something problematic about the epistemic result, then we have good reason to believe that this case does constitute an overgeneralisation worry for ED. On that note, consider the following. Suppose that, through a powerful desire to be liked by everybody, I come to believe that a person has strong affection for me whenever they remember my name. Consequently, I habitually experience the emotional seeming of joy whenever anybody refers to me by name; it emotionally seems to me that this referral is a very good thing for me. At a time $\mathrm{t}^{1}$, when I am aware of these seemings' causal origin in my wishful thinking, they don't justify my evaluative belief that this event is good for me. At a later time $\mathrm{t}^{2}$, when I have forgotten the etiology of these seemings, they do justify my evaluative belief.

Now, this case shares the same general structure as the original overgeneralisation case for ED. Plausibly, however, there's no obvious moral failing in this case. Moreover, it strikes me as unlikely that the issue at play is a zetetic worry pertaining to my poor process of epistemic inquiry given that I'm plausibly not conducting an inquiry when I have the emotional seeming of joy after somebody refers to me by name. According to Friedman (2019), a necessary condition for a subject to count as an inquirer, and to thereby have their process of inquiry subject to zetetic norms of assessment, is that they possess an "interrogative attitude" ( $p$. 299) towards the question at hand, i.e. they're curious or contemplative as to what

\footnotetext{
${ }^{4}$ Note that many seem to share similar intuitions about cases like this. See, for example, Huemer (1999, p. 349) and Annis (1980, p. 326).

5 Thanks to an anonymous reviewer for raising this response.
} 
the answer is. In this case, it's not obvious that I have the goal-directed activity of pursuing an answer to the question as to what any given individual's attitude is towards me; I just have the psychologically immediate experience of joy whenever a person refers to me by name, given my beliefs about what that referral means and my powerful desire to be liked. So, if a subject isn't morally or zetetically blameworthy in a case like this, but there still seems to be something counterintuive about allowing their evaluative belief to be justified by their emotional seemings, then this seems best explained in terms of the subject's specific epistemic failing, such that bestowing their emotional seemings with justificatory power constitutes an over-generalisation problem for ED.

A second argument that the dogmatist might make in response to the overgeneralisation case specifically concerns the worry that, for ED, forgetting key defeating evidence can improve the epistemic status of one's evaluative belief. To dispel this counterintuitive result, the dogmatist might appropriate argumentative resources from discussions of forgotten evidence and defeat in the epistemology of memory literature. One particularly relevant discussion concerns Huemer's (1999) proposal of the following diachronic view of phenomenal conservatism:

A belief is justified full stop if and only if one had an adequate justification for adopting it at some point, and thenceforward one was justified in retaining it. (p. 351).

This view is proposed partially in response to cases of forgotten defeat that are typically levelled against synchronic views of internalist justification. In these cases, a subject forms a belief that $p$ via epistemically irrational means, such as wishful thinking. At a time $\mathrm{t}^{1}$, when the subject is aware of this, her belief that $p$ is unjustified. However, as time passes, the subject forgets the means through which she arrived at $p$, and retains $p$ in memory at $\mathrm{t}^{2}$. The worry is that many synchronic views will deliver the result that $p$ is justified at $\mathrm{t}^{2}$ given that, at this time, the subject's defeater for $p$ is lost to memory. Huemer's diachronic phenomenal conservatism attempts to avoid this result by claiming that a belief is overall justified if and only if the subject was once justified in adopting that belief, i.e., the subject's past mental states matter for the present justificatory status of one's belief. Given that, in the forgotten defeat case, the subject was never justified in adopting $p$ because of its formation via irrational means, Huemer's view avoids the counterintuitive result. Returning to the case at hand, then, perhaps the emotional dogmatist can argue something similar. That is, assuming a view like Huemer's, perhaps one can argue that the xenophobic subject is not justified in her evaluative belief that the person is acting suspiciously at $\mathrm{t}^{2}$ because the evaluative belief was not justified at $\mathrm{t}^{1}$, given her then-awareness of her emotional seemings' etiology.

Here's the problem with this response. Even if diachronic views of this sort turn out to be plausible, ${ }^{6}$ reasoning drawn from these discussions in the epistemology of memory cannot get a foothold on this over-generalisation case for ED given that, here, nothing is being retained in memory. Recall that, in the forgotten defeat cases

\footnotetext{
${ }^{6}$ See Moon (2012) and Smithies (2019) for arguments against diachronic moves of this type.
} 
pertinent to diachronic views like Huemer's, the subject forgets the defeating evidence but retains the belief that $p$ via memory. The problem is that, in ED's overgeneralisation case, the subject does not memorially retain the same belief that the person is acting suspiciously from $\mathrm{t}^{1}$ to $\mathrm{t}^{2}$. Rather, at $\mathrm{t}^{2}$, the subject has another emotional seeming experience which causes the belief which, crucially, is distinct from the belief formed at $\mathrm{t}^{1}$. Because memory is playing no role here, plugging in a view like Huemer's will not be sufficient to dispel the counterintuive result delivered by ED, nor can it absolve the dogmatist of the over-generalisation charge.

So, in summary, if identifying unqualified seemings as justifiers results in an overly permissive account of justification, and if endorsing such an account results in counterintuitive implications, then PD and ED are not plausible accounts of immediate experiential justification.

\section{Restricted emotional dogmatism}

A natural response for the dogmatist to make here is to tighten and finetune their account so as to exclude the over-generalisation cases presented above. One notable example of such a view is proposed by Chudnoff. On Chudnoff's view, it's not sufficient for a perceptual experience to make it seem to you that $p$ in order for it to justify your belief that $p$. Rather, the experience must instantiate the property of having presentational phenomenology with respect to $p$. Chudnoff (2013) sets out the notion of presentational phenomenology as follows:

What it is for an experience of yours to have presentational phenomenology with respect to $\mathrm{p}$ is for it to both make it seem to you that $\mathrm{p}$ and make it seem to you as if this experience makes you aware of a truth-maker for p (p. 37).

Crucially, what distinguishes Chudnoff's view from basic PD is the addition of the truth-maker condition. On this account, if my visual experience of the mug on the desk immediately and defeasibly justifies my belief that there is a mug on the desk, it does so in virtue of having presentational phenomenology with respect to that proposition, i.e. it both makes it seem to me that there is a mug on the desk and makes it seem as if I'm visually aware of an item in my perceptible surroundings that makes that proposition true. Thus, we get the following restricted phenomenal dogmatist view:

Presentationalism: S's perceptual experience is capable of immediately and defeasibly justifying her belief that $p$ if and only if the experience both makes it seem to $\mathrm{S}$ that $p$ and makes it seem as if $\mathrm{S}$ is perceptually aware of a truthmaker for $p$.

There are good reasons to endorse presentationalism. One of the central motivations for the view is that the notion of presentational phenomenology chimes well with various characterisations of the epistemically significant phenomenal character of visual experience offered by phenomenal dogmatists in the literature, 
while providing a more robust diagnosis of this character. ${ }^{7}$ Moreover, the presence of the truth-maker condition makes Chudnoff's account better able to deflect overgeneralisation cases, e.g. if presentationalism is true, then Markie's wishful prospector cannot be justified in their seeming-based belief that the pebble is gold because what makes that proposition true, i.e. the chemical composition of the pebble, is not something that can figure into visual seeming awareness. Therefore, because the visual experience does not make it seem as if the prospector is perceptually aware of a truth-maker for the relevant proposition, it cannot lend justification to the relevant belief.

Now, in light of this development, let's return to the emotions. We can transpose the theoretical machinery of presentational phenomenology over to the case of emotional experience in order to construct the following restricted account of emotional dogmatism:

Restricted Emotional Dogmatism (RED): S's emotional experience is capable of immediately and defeasibly justifying her evaluative belief $e$ if and only if the experience both makes it seem to her that $e$, and makes it seem as if she is emotionally aware of a truth-maker for $e$.

One interesting thing to note here is that RED, insofar as it places epistemic significance on the emotional experience making it seem to you as if you're aware of a truth-maker for an evaluative proposition, fits nicely with the comments provided by Goldie, Tappolet, and Johnston in $\S 1$. Recall that in their respective descriptions of the epistemic power of emotions, Goldie described emotional feelings as capable of "revealing things about the world", while Tappolet suggested that emotional experiences "allow us to be aware of certain features of the world". The suggestion here that emotional experiences provide us with some sort of unique awareness about things out there in the world seems to closely match RED's requirement of emotional experiences making it seem as if we're aware of truthmakers for evaluative propositions, i.e. things out there that make evaluative propositions true. Indeed, Johnston explicitly uses the language of truth-makers insofar as he claims that "affect discloses evaluative truth-makers" (2001, p. 206), and that this (at least partially) explains what he terms the "epistemic authority" (p. 205) of affective experiences. By including the truth-maker condition, then, RED coheres with views about the epistemic import of emotional phenomenology in the surrounding literature, inherits the general advantages of the basic ED account and receives support from a more theoretically robust epistemological framework which avoids the pitfalls of basic dogmatism.

However, RED also faces significant challenges. Before presenting my own critique, let us first address a challenge levelled against RED by Brogaard and Chudnoff (2016). In their analysis, RED is rejected on the grounds that it builds phenomenologically unrealistic contents into the scope of emotional seeming awareness. For Brogaard and Chudnoff, emotional experience cannot bring seeming awareness of truth-makers for evaluative propositions because evaluative properties

\footnotetext{
7 See Chudnoff (2012, p. 56) for further detail.
} 
are not suitable objects of emotional awareness. Crucially, this is because evaluative properties bear a normative dimension; they merit certain emotional responses. For an emotional experience to make it seem as if I'm aware of an evaluative property instantiated by an object, that emotional experience would have to reflexively present itself as being epistemically merited by the object. This, for Brogaard and Chudnoff, cannot be true. Whether an object merits that particular emotional response is not something I can be aware of via my own emotional phenomenology.

I will not pursue this criticism against RED. Instead, I will propose a different challenge which focuses not on RED's putative commitment to controversial phenomenological assertions, but on its commitment to controversial epistemological results. My reason for this is twofold. First, note that whether one finds Brogaard and Chudnoff's challenge compelling relies on their having the intuition that emotional experience cannot bear a very specific kind of self-reflexive phenomenology. This doesn't strike me as a commonly held intuition. There are those in the literature who, at the very least, are amenable to the suggestion that emotions can be experienced as being epistemically merited with respect to their objects, and some even propose accounts of emotional phenomenology in which this is explicitly the case. ${ }^{8}$ Second, and relatedly, it seems at least prima facie plausible that our intuitions have significantly more reliability and argumentative traction within the domain of epistemological theorising, given the frequency with which counterexamples are cited as compelling objections to epistemological views. Our intuitions when it comes to specific introspective phenomenological claims, on the other hand, are plausibly less widely-shared, less reliable, and less dialectically compelling. For these reasons, $\$ 3.1$ will solely pursue the forthcoming epistemological challenge against RED.

\subsection{Objection: the dilemma of evaluative truth-makers}

Here, I argue that RED's inclusion of the truth-maker condition spells serious trouble for the view. Specifically, RED faces a dilemma in what seeming awareness of truth-makers for evaluative propositions consists in. Take an experience of fear towards an approaching snake. In order for that experience of fear to justify the evaluative belief that the snake is fearsome, the experience must both make it seem to you that the snake is fearsome and make it seem as if you're emotionally aware of a truth-maker for that evaluative proposition. But what is the truth-maker for this proposition? RED, as expressed thus far, is silent as to whether the truth-maker consists in the evaluative property of fearsomeness itself, or whether it consists in the non-evaluative properties instantiated by the snake that give rise to the evaluative property of fearsomeness, i.e. the sharp fangs, the aggressive movements, and so forth. Call these 'the evaluative property reading' and 'the non-evaluative property reading' of the truth-maker condition respectively. The problem is that neither of these options looks promising for RED.

\footnotetext{
${ }^{8}$ See Mitchell (2017) and Poellner (2016) for explicit endorsements of the idea that emotions are capable of bearing this self-reflexive phenomenal character.
} 
Let's begin with the evaluative property reading, which can be spelled out as follows:

$\mathrm{RED}^{\mathrm{EP}}$ : S's emotional experience is capable of immediately and defeasibly justifying her evaluative belief $e$ if and only if the experience both makes it seem to her that $e$ and makes it seem as if she's emotionally aware of the evaluative property putatively instantiated by the object.

Immediately, a problem arises here. Namely, while the inclusion of the truthmaker condition seems to suitably restrict dogmatism in the perceptual case, it's not at all clear that this reading of the truth-maker condition restricts RED at all. Reconsider Brady's suspicious interviewer. The worry is that $\mathrm{RED}^{\mathrm{EP}}$ can't exclude the interviewer's emotional experience of suspicion because their experience satisfies both the seeming condition and the truth-maker condition. That is, insofar as the emotional experience already makes it seem to the interviewer that the candidate is duplicitous (and they're not aware of any reason to distrust this seeming), then plausibly their experience of suspicion also makes it seem to them that the candidate instantiates the property of 'duplicitousness'. The evaluative property reading of the truth-maker condition doesn't seem to be adding any further requirement to emotional dogmatism, given that any emotional experience which satisfies the seeming condition will also satisfy the truth-maker condition. What else could it mean for an emotional experience to make it seem to you that the candidate is duplicitous, other than making it seem as if you're aware of the evaluative property of 'duplicitousness' putatively instantiated by the candidate? Naturally, then, $\mathrm{RED}^{\mathrm{EP}}$ will continue to over-generalise to problematic cases precisely because, in practice, it's no different to ED.

At this point, the defender of $\mathrm{RED}^{\mathrm{EP}}$ may argue that the case is under-described. In response to this over-generalisation worry, they might attempt to re-describe the case in order to motivate the plausibility of conceding justification to the interviewer. They may suggest, for instance, that the interviewer's emotional experience of suspicion makes it seem as if they're emotionally aware of the duplicitousness instantiated by the candidate because the interviewer is picking up on subtle duplicitous-making features of the candidate, i.e. that their emotional seeming awareness of duplicitousness is caused by their perception of certain mannerisms and micro-behaviours indicative of duplicitousness, such as avoiding the gaze of the interview panel, excessive talking, smirking, etc. Thus, the defender of $\mathrm{RED}^{\mathrm{EP}}$ might argue that the emotional experience makes it seem as if they're emotionally aware of the property 'duplicitousness' instantiated by the candidate because they're aware of the relevant pattern of non-evaluative properties. If this is the case, then conceding justification on the basis of these emotional seemings doesn't seem problematic.

The problem with this response is that $\mathrm{RED}^{\mathrm{EP}}$ lacks the ability to distinguish between a case like this, i.e. a case in which the emotional seeming awareness of duplicitousness is caused by a seeming awareness of a pattern of duplicitous-making features of the candidate, and a case in which the emotional seeming awareness of 'duplicitousness' is caused by epistemically dubious cognitive biases (e.g. suppose that the candidate is a woman and the interviewer is unknowingly biased against 
women). The worry is that, insofar as the epistemically relevant emotional seemings-i.e. the seeming that the candidate is duplicitous and the seeming awareness of the evaluative property 'duplicitousness' instantiated by the candidate - can be grounded in either of these causal explanations, $\mathrm{RED}^{\mathrm{EP}}$ doesn't have the tools to differentiate the good and bad cases; both types of emotional seemings (i.e. those produced by epistemically legitimate means and those produced by epistemically illegitimate means) have the same justificatory power. This is a bad result.

So, if the source of RED's continued vulnerability to the over-generalisation problem is conceiving of truth-makers for evaluative propositions as evaluative properties themselves, why not abandon this claim and insist instead that the truthmaker for an evaluative proposition is the relevant set of non-evaluative properties instantiated by the object which would make the proposition true? This is the nonevaluative property reading, and can be spelled out as follows:

RED $^{\text {NEP }}$ : S's emotional experience is capable of immediately and defeasibly justifying her evaluative belief $e$ if and only if the experience both makes it seem to her that $e$ and makes it seem as if she's emotionally aware of the set of non-evaluative properties that, if instantiated, would give rise to the relevant evaluative property, and so make $e$ true.

The attraction of this reading is that, unlike $\mathrm{RED}^{\mathrm{EP}}$, it avoids obvious overgeneralisation cases like the biased interviewer. Recall that, in this case, the interviewer's emotional seeming awareness of the candidate's duplicitousness is caused by their bias against women. This case would not meet the requirements of $\mathrm{RED}^{\mathrm{NEP}}$ precisely because the interviewer's emotional experience is not making it seem as if they're aware of the set of non-evaluative properties that would make the proposition 'the candidate is duplicitous' true. Rather, their experience is being triggered by the combination of their sexist bias and their perception of the candidate's gender. Clearly, mere seeming awareness of the candidate's gender does not amount to seeming awareness of the candidate instantiating particular nonevaluative properties which would make the proposition 'the candidate is duplicitous' true. Thus, RED ${ }^{\mathrm{NEP}}$ avoids the charge of over-generalisation because it can epistemically differentiate between the good case (i.e. the case in which the interviewer's emotional seemings of duplicitousness are caused by their perception of duplicitous-making non-evaluative features of the candidate), and the bad case (i.e. the case in which the interviewer's emotional seemings of duplicitousness are caused by their perception of the candidate's gender and their bias against women).

The problem, however, is that $\mathrm{RED}^{\mathrm{NEP}}$ is now too restrictive. If we identify these conjunctions of non-evaluative properties as truth-makers, then very few of our emotional experiences would be capable of bearing justificatory power. It seems that only very basic emotional experiences, like fear of a snake or disgust towards spoiled milk, for example, are reliably capable of bringing the required wideranging emotional seeming awareness of the relevant non-evaluative properties that would make the relevant proposition (e.g. 'the snake is fearsome', or 'the spoiled milk is disgusting') true. Emotional experiences which do not figure into this very basic category often don't bring awareness of the relevant non-evaluative 
properties. ${ }^{9}$ Take an emotional experience of awe towards a piece of artwork which does not bring full seeming awareness of the non-evaluative properties which would make the proposition 'that artwork is beautiful' true, or an experience of amusement towards a particular state of affairs which does not bring seeming awareness of the particular amusement-making non-evaluative properties. Despite the absence of such fine-grained seeming awareness, it seems entirely possible that emotional experiences of this sort are capable of providing a positive epistemic contribution to the status of the corresponding evaluative beliefs. Thus, robbing these emotions of immediate justificatory power on the basis of their not fulfilling the strict phenomenological requirements for $\mathrm{RED}^{\mathrm{NEP}}$ strikes me as bad news for the view.

Here, there are two possible responses available to the defender of RED ${ }^{\mathrm{NEP}}$. The first of which is to concede that, understood this way, the view ends up being restrictive but deny that this is problematic. Indeed, the defender of $\mathrm{RED}^{\mathrm{NEP}}$ might stress that the lesson to be learned from the over-generalisation problem is that we should be casting a narrow net around the emotional experiences capable of bearing justificatory power. We want to rule out cases in which emotional seemings look like they're not grounded in epistemically legitimate observations of the relevant non-evaluative properties, and the best way of doing this is to impose strict constraints on what counts as emotional seeming awareness of truth-makers. If a consequence of this is that relatively complex emotional experiences which do not bring seeming awareness of the relevant non-evaluative properties end up getting ruled out of the account (insofar as they do not make it seem as if one is emotionally aware of a truth-maker for the relevant evaluative proposition), then so be it. The worry with conceding epistemic austerity here, however, is that one desideratum for a plausible version of a justificatory thesis of emotion is that it can account for how a broad catalogue of our evaluative beliefs can be justified by emotional experiences. If endorsing $\mathrm{RED}^{\mathrm{NEP}}$ means that we can only consider very basic emotional experiences as capable of bearing justificatory ability, then our dogmatist approach to emotional justification is failing to provide a satisfactory picture of the immediate justificatory capacity of emotional experience.

Secondly, the objector might argue that in these scenarios-take the amusement case, for example - my emotional experience is, in fact, making it seem as if I'm aware of the relevant collection of non-evaluative properties which would make the event amusing, I just can't articulate exactly what those properties are. One suggestion in support of this might be something like the following. When prompted, i.e. when asked 'what's so funny?', I can gesture vaguely towards the features of the situation that make it amusing, such as the particular comment made, the context in which it was made, and so forth, even if I can't express the amusingmaking minutia. In other words, I'm not at a complete loss as to what it is about the situation that makes it amusing, and this is all that's needed for evidence of emotional seeming awareness of the relevant conjunction of non-evaluative

\footnotetext{
${ }^{9}$ Echeverri (2019) makes a similar point about the limits of awareness when it comes to the nonevaluative properties which constitute or give rise to the evaluative property in question, arguing that there are many relational properties which contribute towards an object exemplifying a given evaluative property, most of which we are "typically" (p. 550) not aware of.
} 
properties. Therefore, we can tell some story about having emotional seeming awareness of the relevant truth-maker in these cases, and RED ${ }^{\mathrm{NEP}}$ doesn't end up being objectionably restrictive with respect to the kinds of emotional experiences is bestows with justificatory power.

The problem with this response is that further ambiguity in what emotional seeming awareness of truth-makers consists in raises difficult questions for RED ${ }^{\mathrm{NEP}}$. If all that matters for emotional seeming awareness of truth-makers is that the experience makes the subject capable of gesturing towards the non-evaluative features of the object which would make the relevant evaluative proposition true, then it becomes less clear that $\operatorname{RED}^{\mathrm{NEP}}$ is able to rule out problematic cases. Take the suspicious interviewer whose emotional seemings that the candidate is duplicitous are caused by sexist bias. Plausibly, their emotional experience of suspicion will make them capable of saying something about what seems to make the candidate duplicitous (e.g. "there's just something about them"), but this still seems insufficient for the interviewer to be justified in their belief that the candidate is duplicitous. Substantively relaxing the notion of awareness in order to let in cases where the emotional experience doesn't make it seem as if one is aware of (i.e. able to identify) all of the relevant non-evaluative properties runs the risk of letting the epistemically illegitimate cases like biased suspicious interviewer in through the back door.

In summary, RED is confronted with a troubling dilemma. Either we identify evaluative properties themselves as the truth-makers for evaluative propositions $\left(\mathrm{RED}^{\mathrm{EP}}\right)$, in which case the view continues to over-generalise, or we identify the relevant aggregate of non-evaluative properties as truth-makers for evaluative propositions $\left(\mathrm{RED}^{\mathrm{NEP}}\right.$ ), in which case the view rules out emotional experiences which, plausibly, are capable of immediately justifying the relevant evaluative beliefs. If endorsing RED means that we must commit to either an objectionably profligate account of emotional justification or instead one which is objectionably austere, then RED does not provide a suitable framework for thinking about the immediate justificatory power of emotional experiences.

\section{Alternative restricted emotional dogmatism}

One question the reader might have at this point is whether there exists an alternative instantiation of a restricted emotional dogmatist view. That is, if the addition of the Chudnoff-inspired truth-maker condition fails to make ED plausible, then perhaps we can look elsewhere for an additional condition to crystallise the view. Here, I will consider two alternative versions of restricted emotional dogmatism inspired by restricted phenomenal dogmatist accounts provided by McGrath and Markie, and argue that neither of these views can provide a plausible framework for an emotional dogmatist view. 


\subsection{Receptive seemings emotional dogmatism}

Recall the gold prospector example which began our discussion of the overgeneralisation problem back in \$2.1. In this case, the expert prospector's perceptual seeming that the pebble is gold arises from their learned identification skills, while the wishful prospector's perceptual seeming that the pebble is gold arises from their desire to discover gold. The problem for basic PD was that it was unable to account for the intuitive verdict that, while the expert may be justified on the basis of their perceptual seemings, it is implausible that the wishful prospector's seeming has the same justificatory ability.

In light of counterexamples like this, McGrath (2013) aims to construct a restricted version of phenomenal dogmatism which manages to exclude problematic cases while also striving to retain the initial attractions of basic views. On this note, McGrath suggests that what's going wrong in cases like the wishful prospector is that the perceptual seeming has what he refers to as a "quasi-inferential" (p. 228) basis, i.e. the wishful prospector's perceptual seeming that the pebble is gold does not arise directly from perception but instead arises via an inference-like transition or 'jump' from the base perceptual seeming that there is a yellowish pebble. The relationship between the seemings here is 'quasi-inferential' insofar as exchanging the seemings with corresponding beliefs containing the same propositional contents would render the transition as an instance of inference between beliefs. For McGrath, it is only seemings which do not have such a quasi-inferential basis-i.e. receptive seemings - which are capable of providing immediate and defeasible justification to the relevant belief. At best, seemings with a quasi-inferential basis might be capable of conferring mediate justification to the relevant belief, but only if it's an epistemically good quasi-inference, i.e. only if the content of the base seeming adequately supports the content of the quasi-inferred seeming.

Applying this to the example at hand, the wishful prospector has a receptive perceptual seeming that there is a yellowish pebble. On McGrath's account, the prospector would be immediately justified in believing that there is a yellowish pebble on the basis of this seeming. However, the prospector's desire to discover gold intervenes and produces a quasi-inferred perceptual seeming that the pebble is gold. Because this perceptual seeming is quasi-inferred from the base perceptual seeming that there is a yellowish pebble, it is not capable of immediately and defeasibly justifying the prospector's belief that the pebble is gold. Moreover, we can see that this quasi-inference taking place is not an epistemically legitimate one. The seeming with the content 'there is a yellowish pebble' does not sufficiently support the content of the quasi-inferred seeming, i.e. 'the pebble is a gold nugget'. Hence, the wishful prospector is in no way justified in their belief that the pebble is gold on the basis of their perceptual seemings.

So, if this looks like a plausible view with respect to perceptual seemings, we can construct an analogous emotional dogmatist view as follows:

Receptive Seemings Emotional Dogmatism (RSED): S's emotional experience is capable of immediately and defeasibly justifying her evaluative belief that an object $\mathrm{O}$ instantiates an evaluative property $\mathrm{E}$ if and only if (i) the 
experience makes it seem to her that $\mathrm{O}$ is $\mathrm{E}$, and (ii) this seeming does not have a quasi-inferential basis.

Now, to some degree, the question of whether RSED constitutes an improvement on RED hinges on whether RSED gives us the right result in emotional overgeneralisation cases; whether it correctly diagnoses what's going wrong with the suspicious interviewer's emotional seeming, for example, and has the philosophical tools to exclude it from being capable of conferring justification. Here's the problem. While the notion of receptivity may be plausible with respect to perceptual seemings and perceptual over-generalisation cases, it's not obvious that it translates well to the emotional case. There's a question of whether any emotional seemings are receptive, and not quasi-inferred from other seemings, given that emotions have what Deonna and Teroni (2012) refer to as "cognitive bases" (p. 5). That is, unlike perceptions, emotions rely on base mental states such as perceptions, beliefs, and so forth. I can't experience fear in response to the approaching snake without in some way perceiving the snake and its fearsome-making features. The same is not true of visually perceiving the snake; my visual experience of the snake does not presuppose a further mental state in the same way that my emotional experience does. In light of this fact, then, we might wonder how any emotional experience can involve a seeming that an object instantiates a particular evaluative property without that seeming being quasi-inferred from non-emotional seemings pertaining to the non-evaluative features of the object. ${ }^{10}$

This is a problem because, if it is the case that all or most emotional seemings are quasi-inferred from the seemings of their cognitive bases (i.e. perceptual seemings, introspective seemings, etc.), it looks like RSED can't explain the intuitive epistemic difference between legitimately and illegitimately produced emotional seemings. Reconsider two versions of the suspicious interviewer case. In one scenario, the interviewer's emotional seeming that the candidate is duplicitous is caused by legitimate observations of duplicitous-making features of the candidate, whereas the other scenario involves the emotional seeming being caused by illegitimate background biases. For RSED, what has to be going wrong in the bad case is that the interviewer's emotional seeming that the candidate is duplicitous is quasi-inferred from another seeming, and is thereby incapable of lending immediate justification to the evaluative belief that the candidate is duplicitous. But, as we've seen above, it looks like both the good and the bad case involve quasi-inferred emotional seemings. If merely being non-receptive makes a seeming incapable of conferring immediate justification, then RSED generates the same result for both the good and bad cases of suspicious interviewer.

In response, the defender of RSED might argue that the view can still explain the intuitive difference in epistemic capacity between the emotional seemings involved

\footnotetext{
10 There's a question here as to whether the emotions' dependence on their cognitive bases bars them from ever conferring immediate justification to evaluative belief. This is an important and complex question, and has been discussed at length by Milona and Naar (2020) and Cowan (2018). Given that this is pertinent to anybody interested in bestowing emotional experience with immediate justificatory power, and given my focus on problems specific to dogmatist views, a full discussion of this challenge is beyond the scope of what I can discuss here.
} 
in both cases. That is, they may point to the difference in epistemic quality in each quasi-inference as what explains the intuition that the emotional seeming produced by legitimate observations is better epistemically placed than the seeming produced by illegitimate bias. Recall that a quasi-inferential basis need not rob the seeming of all of its justificatory power. If it is a good quasi-inference, i.e. if the content of the base seeming adequately supports the content of the quasi-inferred seeming, then the quasi-inferred seeming can transmit mediate justification to the relevant belief. The defender of RSED might argue that in the good case, i.e. the case in which the emotional seeming that the candidate is duplicitous is quasi-inferred from the perceptual seeming which has as its content the relevant conjunction of duplicitousmaking non-evaluative features of the candidate (i.e. their behaviours and mannerisms), the quasi-inference is legitimate insofar as the content of the base perceptual seeming adequately supports the content of the emotional seeming. On the other hand, consider the bias case. Presumably, the emotional seeming that the candidate is duplicitous will be quasi-inferred from perceptual seemings with different contents, e.g. if it's a sexist bias, then the emotional seeming that the candidate is duplicitous will be quasi-inferred from the base perceptual seeming that the candidate is a woman. Clearly, this is not a legitimate quasi-inference. In other words, there's an illegitimate 'jump' in the bias quasi-inference that isn't present in the good case, and this is what explains the difference in epistemic status between the two cases.

Even if this is a plausible way of explaining the intuitive difference between the two suspicious interviewer cases, it still doesn't get us where we want to go given that we've been interested in how emotional phenomenology can immediately justify our evaluative beliefs. If it is the case that emotional seemings can only ever transmit mediate justification generated by perceptual (or introspective, etc.) seemings, then RSED cannot account for emotional experience as a source of unmediated epistemic justification. Recall that one of the main selling points of emotional dogmatism concerns its ability to provide low-cost justification to a rich catalogue of our evaluative beliefs. This capacity, which is essential for providing dogmatists with the resources to answer sceptical worries pertaining to the acquisition of various epistemic goods, crucially depends on the immediacy of the justification. If the justification provided by seemings must instead meet further epistemic requirements, such as being suitably related to the content of the subject's non-emotional seemings and existing justified beliefs, then we give argumentative sway back to the sceptic, and thereby lose the distinctive virtue of dogmatism. Therefore, because eliminating immediacy from dogmatism eliminates a substantive percentage of the theory's philosophical attractions, and because RSED requires eschewing immediacy, McGrath's receptivity-based view cannot be a suitable theoretical framework for emotional dogmatism.

\subsection{Knowledge-how emotional dogmatism}

Finally, let's consider Markie's view. Returning to the gold prospector case, a natural suggestion as to why the expert prospector's perceptual seeming enjoys justificatory power is that the expert knows what gold looks like; the novice doesn't 
have anything close to this knowledge. One way of spelling out the problem with basic PD is that it can't account for the fact that this ought to make a difference between the epistemic status of the expert's and novice's belief. In light of this, Markie (2013) proposes a qualified view of phenomenal dogmatism which restricts the type of seemings capable of possessing justificatory power to seeming experiences brought about by the agent's exercise of the relevant knowledge-how capacity.

To summarise Markie's view, merely having a perceptual seeming is insufficient for immediate and defeasible justification. A further condition must be met, namely that the subject must have the relevant knowledge-how capacity to recognise the relevant property and the seeming must be appropriately related to that capacity, i.e. the knowledge-how plays a substantive causal role in bringing about the seeming. On Markie's view, what possessing a knowledge-how capacity amounts to is the subject possessing a disposition to experience the relevant seemings upon perceptually apprehending certain features of the object in question, e.g. the expert prospector has the knowledge-how capacity to perceptually identify gold nuggets insofar as they are disposed to have the perceptual seeming that a pebble is gold when apprehending certain gold-making features of the object. Moreover, that subject's disposition is, as Markie puts it, "determined by" (p. 264) their having the right sort of background information, e.g. that an object which has certain features and looks a certain way is gold. Finally, on Markie's account, having this background information is a matter of having evidence that justifies the subject in believing, in this case, that an object which looks a certain way is gold.

So, if this view looks like it's generating the right result in the perceptual case, we can transpose it into an emotional dogmatist view as follows:

Knowledge-How Emotional Dogmatism (KHED): S's emotional experience is capable of immediately and defeasibly justifying her evaluative belief that an object $\mathrm{O}$ instantiates an evaluative property $\mathrm{E}$ if and only if (i) the experience makes it seem to her that $\mathrm{O}$ is $\mathrm{E}$, and (ii) the experience makes it seem to her that $\mathrm{O}$ is $\mathrm{E}$ in virtue of her knowledge of how to emotionally identify something as being $\mathrm{E}$.

For KHED, my emotional experience of fear towards the snake is capable of immediately and defeasibly justifying my evaluative belief that the snake is fearsome if and only if my experience makes it seem to me that the snake is fearsome and I have this emotional seeming as the result of my knowledge of how to emotionally identify something as fearsome. Analogously to the perceptual case above, a subject's knowledge-how capacity to emotionally identify something as fearsome involves the possession of a disposition to experience emotional seemings of fearsomeness upon attending to certain features of the object or situation. Moreover, I possess this disposition at least partly by virtue of my having the relevant background information, i.e. what makes fearsome things fearsome.

The good news for KHED is that the addition of the knowledge-how condition on seemings places the view in a much better position than RED to be able to handle over-generalisation cases. Take the case in which the interviewer's suspicious emotional seemings towards the candidate are produced by an illegitimate bias as 
opposed to legitimate observations of duplicitous-making features of the candidate. KHED is able to provide a straightforward explanation as to why the interviewer's emotional seemings do not justify them in believing that the candidate is duplicitous, i.e. the suspicious seeming is experienced by virtue of the interviewer harbouring illicit biases, not by virtue of their knowledge of how to emotionally identify duplicitousness. The interviewer whose emotional seemings do arise as a result of legitimate observations of duplicitous-making features, however, plausibly does enjoy justification for their belief that the candidate is duplicitous insofar as their experiencing the seemings as a result of those legitimate observations is an exercise of her knowledge-how capacity to identify duplicitousness.

However, KHED faces two problems. The first of which is that, again, it's not clear that this account paints a plausible picture of immediate justification. Since justification-conferring emotional seemings must be the result of an exercise of a knowledge-how capacity, and since this capacity is determined by the possession of background information that would justify the relevant evaluative proposition, it's not obvious that KHED is capturing the phenomenon that we set out to explain. The second worry is that attributing so much weight to the possession of the relevant background information that determines one's disposition to have the relevant emotional seemings (and thereby the relevant knowledge-how capacity) threatens to render emotional phenomenology epistemically superfluous. That is, there's a serious question of what justificatory work the emotional seemings are doing if the brunt of the epistemic labour has already been done by the subject insofar as she has the background information required to justify her belief that a given object instantiates the relevant evaluative property.

So, while KHED looks promising insofar as it seems better placed to handle overgeneralisation cases, we see on closer inspection that it is unable to explain the immediate justificatory power of emotional experience, and threatens to make emotional phenomenology epistemically superfluous. Markie's knowledge-how account, then, is not a suitable framework for an analogous emotional dogmatist view.

\subsection{Summing up}

Here, I have considered and rejected four possible emotional dogmatist views. Basic emotional dogmatism fails in virtue of being too liberal with respect to the types of emotional experiences it bestows with justificatory power, and the attempt to restrict emotional dogmatism with the Chudnoff-inspired truth-maker condition fails in virtue of falling foul to a troubling dilemma in what seeming awareness of truthmakers consists in. I've also aimed to show that alternative options for restricting emotional dogmatism, i.e. views analogous to those advanced by McGrath and Markie, cannot provide a plausible account as to how emotional experience can immediately justify evaluative belief.

To be clear, the purpose of this discussion has not been to provide a conceptual argument for the failure of every instantiation of the emotional dogmatist view, nor have I endeavoured to show that emotional experience is altogether incapable of immediately and defeasibly justifying belief. Rather, by levelling these arguments 
against ED, RED, RSED, and KHED, I have aimed to build an inductive case against the possibility of a plausible emotional dogmatist view. In lieu of an undiscovered dogmatist instantiation which does not fall foul to the above objections, we have good reason to reject the idea that emotional phenomenology is what makes emotional experience capable of immediately justifying evaluative belief.

What remains an open question is whether emotional seeming states might be capable of lending justification to evaluative belief mediated by other mental states and beliefs. As we've seen from $\$ 4.1$ and $\$ 4.2$, it may be possible to provide an explanation as to how emotional seemings can perform some epistemic role in transmitting justification initially generated by either receptive perceptual seemings in McGrath's case or by the background information which constitutes the relevant knowledge-how capacity for Markie. Determining whether emotional experience has this epistemic capacity, however, is a task for another paper. For now, I conclude that the prospects of emotional dogmatism, as a straightforward analogue of phenomenal dogmatism, are bleak.

Acknowledgements Many thanks to Michael Brady, Robert Cowan, and Jack Lyons for helpful comments on earlier drafts of this paper. Thanks also to two anonymous referees for their valuable and constructive feedback.

Open Access This article is licensed under a Creative Commons Attribution 4.0 International License, which permits use, sharing, adaptation, distribution and reproduction in any medium or format, as long as you give appropriate credit to the original author(s) and the source, provide a link to the Creative Commons licence, and indicate if changes were made. The images or other third party material in this article are included in the article's Creative Commons licence, unless indicated otherwise in a credit line to the material. If material is not included in the article's Creative Commons licence and your intended use is not permitted by statutory regulation or exceeds the permitted use, you will need to obtain permission directly from the copyright holder. To view a copy of this licence, visit http:// creativecommons.org/licenses/by/4.0/.

\section{Funding}

\section{References}

Annis, D. (1980). Memory and justification. Philosophy and Phenomenological Research, 40(3), 324-333.

Brady, M. (2013). Emotional Insight: The Epistemic Role of Emotional Experience. Oxford: Oxford University Press.

Brogaard, B., \& Chudnoff, E. (2016). Against emotional dogmatism. Philosophical Issues, 26(1), 59-77.

Chudnoff, E. (2012). Presentational phenomenology. In S. Miguens \& G. Preyer (Eds.), Consciousness and subjectivity (pp. 51-72). Heusenstamm: Ontos Verlag.

Chudnoff, E. (2013). Intuition. Oxford: Oxford University Press.

Cowan, R. (2018). Epistemic sentimentalism and epistemic reason-responsiveness. In A. Bergqvist \& R. Cowan (Eds.), Evaluative perception (pp. 219-237). Oxford: Oxford University Press.

Deonna, J., \& Teroni, F. (2012). The emotions: A philosophical introduction. New York: Routledge.

Döring, S. (2007). Seeing what to do: Affective perception and rational motivation. Dialectica, 61(3), 363-394.

Echeverri, S. (2019). Emotional justification. Philosophy and Phenomenological Research, 98(3), $541-566$. 
Friedman, J. (2019). Inquiry and belief. Nô̂s, 53(2), 296-315.

Goldie, P. (2004). Emotion, feeling, and knowledge of the world. In R. C. Solomon (Ed.), Thinking about feeling: Contemporary philosophers on Emotions (pp. 91-106). Oxford: Oxford University Press.

Huemer, M. (1999). The problem of memory knowledge. Pacific Philosophical Quarterly, 80(4), $346-357$.

Huemer, M. (2013). Phenomenal conservatism über alles'. In C. Tucker (Ed.), Seemings and justification: new essays on dogmatism and phenomenal conservatism (pp. 328-350). Oxford: Oxford University Press.

Johnston, M. (2001). The authority of affect. Philosophy and Phenomenological Research, 63(1), $181-214$.

Markie, P. (2005). The mystery of direct perceptual justification. Philosophical Studies, 126(3), 347-373.

Markie, P. (2013). Searching for true dogmatism'. In C. Tucker (Ed.), Seemings and justification: new essays on dogmatism and phenomenal conservatism (pp. 248-269). Oxford: Oxford University Press.

McGrath, M. (2013). Phenomenal conservatism and cognitive penetration: The bad basis counterexamples. In C. Tucker (Ed.), Seemings and justification: new essays on dogmatism and phenomenal conservatism (pp. 225-247). Oxford: Oxford University Press.

Milona, M., \& Naar, H. (2020). Sentimental Perceptualism and the challenge from cognitive bases. Philosophical Studies, 177, 3071-3096.

Mitchell, J. (2017). The epistemology of emotional experience. Dialectica, 71(1), 57-84.

Moon, A. (2012). Knowing without evidence. Mind, 121(482), 309-331.

Pelser, A. (2014). Emotion, Evaluative Perception, and Epistemic Justification. In S. Roeser \& C. Todd (Eds.), Emotion and value (pp. 107-123). Oxford: Oxford University Press.

Poellner, P. (2016). Phenomenology and the perceptual model of emotion. Proceedings of the Aristotelian Society, 116(3), 261-288.

Smithies, D. (2019). On the global ambitions of phenomenal conservatism. Analytic Philosophy, 60(3), 206-244.

Tappolet, C. (2016). Emotion, Values, and Agency. Oxford: Oxford University Press.

Tucker, C. (2010). 'Why open-minded people should endorse dogmatism. Philosophical Perspectives, 24(1), 529-545.

Tucker, C. (2013). Seemings and justification: An introduction. In C. Tucker (Ed.), Seemings and justification: New essays on dogmatism and phenomenal conservatism (pp. 1-29). Oxford: Oxford University Press.

Publisher's Note Springer Nature remains neutral with regard to jurisdictional claims in published maps and institutional affiliations. 